\title{
Sellar-Suprasellar Extraventricular Choroid Plexus Papilloma : A Case Report and Review of the Literature
}

\author{
Fatih Keskin, M.D., ${ }^{1}$ Fatih Erdi, M.D., ${ }^{1}$ Bülent Kaya, M.D., ${ }^{1}$ Hatice Toy, M.D. ${ }^{2}$ \\ Departments of Neurosurgery, ${ }^{1}$ Pathology, ${ }^{2}$ Meram Faculty of Medicine, Necmettin Erbakan University, Konya, Turkey
}

\begin{abstract}
Choroid plexus papillomas (CPPS) are relatively rare neuroectodermal tumors that develop from choroid plexus epithelial cells and are usually restricted to the ventricles. Extraventricular CPPs are very unusual and can be difficult to diagnose and treat. A 50-year-old male patient was admitted to our clinic complaining of headache and visual deterioration. Neurological examination found no abnormalities except decreased light perception and secondary optic atrophy in the left eye. Endocrine testing revealed normal levels of hormones produced by the pituitary and target glands. Magnetic resonance imaging of the brain revealed a huge regular-shaped lesion in the sellar-suprasellar region occupying the sella turcica and extending into the suprasellar cistern and planum sphenoidale. The lesion was completely excised by microsurgery via an ordinary left-sided pterional approach. Histopathology identified the lesion as a choroid plexus papilloma. Following the case report, literature on the origin, differential diagnosis, and treatment of this rare tumor is reviewed.
\end{abstract}

Key Words : Choroid plexus papilloma · Extraventricular · Sellar-suprasellar · Magnetic resonance imaging · Pathology.

\section{INTRODUCTION}

Choroid plexus papillomas (CPPs) are relatively rare neuroectodermal tumors that develop from choroid plexus epithelial cells and account for $0.4-0.6 \%$ of all primary brain tumors ${ }^{7)}$. CPPs are usually restricted within the trigone of the lateral and fourth ventricles and have clear borders ${ }^{7)}$. In adults, CPPs generally develop in the fourth ventricle, but in rare cases they can occur in extraventricular sites such as the cerebral parenchy$\mathrm{ma}^{7)}$, cerebellopontine angle ${ }^{12,13)}$, or suprasellar region ${ }^{9,17)}$. The exact mechanism by which CPPs arise at extraventricular sites remains unclear and is subject to some controversy. In this report we present an unusual case of sellar-suprasellar CPP and review the literature.

\section{CASE REPORT}

A-50-year-old male patient was admitted to our clinic with headache and a 6-month history of progressive deterioration of vision in the left eye. Vision from the right eye was normal and no bitemporal hemianopsia or symptoms of endocrine disturbance were observed. He had also suffered headache for the last month. The only abnormal findings on neurological were de- creased perception of light and secondary optic atrophy in the left eye. Endocrine testing revealed normal levels of hormones produced by the pituitary and target glands.

Magnetic resonance imaging (MRI) of the brain revealed a huge regular-shaped lesion in the sellar-suprasellar region occupying the sella turcica and extending into the suprasellar cistern and planum sphenoidale. On T1-weighted images, the majority of the mass was of low intensity, suggesting a cystic lesion. The right side base of the lesion, just above the suprasellar carotid artery, contained a hyperintense contrast-enhanced nodule. On T2-weighted images, the lesion was hyperintense, also compatible with a cystic lesion. The suprasellar cistern was filled and the optic chiasm and third ventricle were elevated by the lesion (Fig. 1). According to these findings, the lesion was diagnosed as a craniopharyngioma, pituitary adenoma, cystic astrocytoma or ependymoma.

The tumor was approached via a left pterional craniotomy. The cystic component of the tumor was reached first and upon opening the cyst wall, the contents were aspirated. On the basal right side of the lesion, a yellowish vascular nodule adjacent to the suprasellar internal carotid artery was revealed (Fig. 2) and completely excised while preserving the internal carotid artery. During the operation, no communication with the third or lat-

- Received : July 1, 2014 • Revised : November 18, 2014 •Accepted : December 5, 2014

- Address for reprints : Fatih Erdi, M.D.

Department of Neurosurgery, Meram Faculty of Medicine, Necmettin Erbakan University, Meram, Konya 42080, Turkey

Tel : +90-332 223 7783, Fax : +90-332 223 6181, E-mail : mfatiherdi@hotmail.com

- This is an Open Access article distributed under the terms of the Creative Commons Attribution Non-Commercial License (http://creativecommons.org/licenses/by-nc/3.0) which permits unrestricted non-commercial use, distribution, and reproduction in any medium, provided the original work is properly cited. 

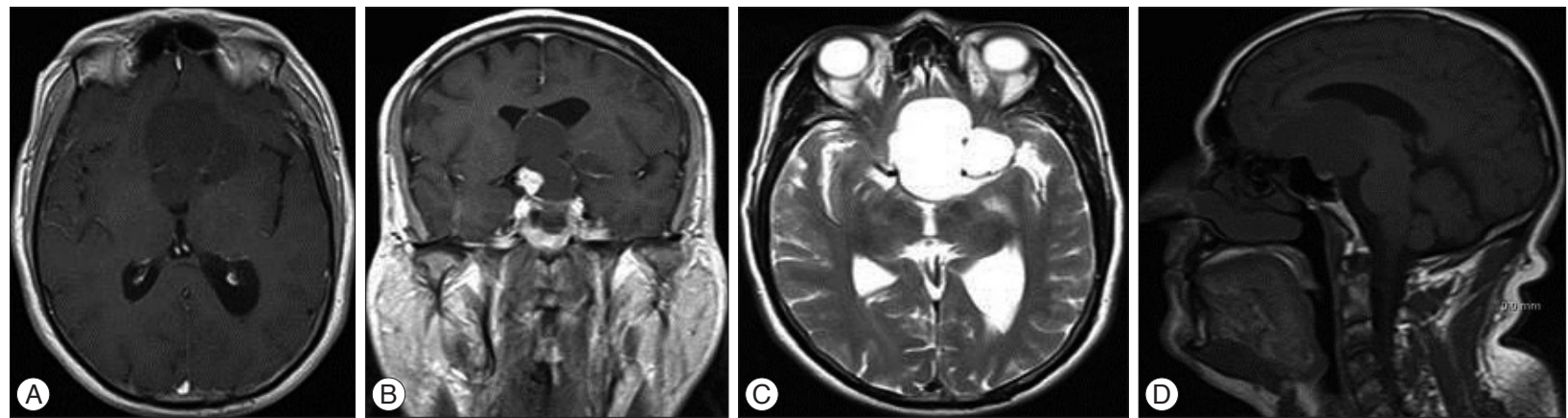

Fig. 1. Radiological findings. A : T1-weighted axial MRI reveals a hypointense regular-shaped cystic lesion at the ventricular border. B : Contrastenhanced T1-weighted coronal MRI reveals that the lesion compresses the optic chiasma and elevates the third ventricle and identifies the contrastenhanced solid hyperintense nodule at the right floor of the lesion, just above the suprasellar internal carotid artery. C : Hyperintense cystic lesion on T2-weighted axial MRI. D : Tumoral invasion of the planum sphenoidale, whole sellar area, and suprasellar cistern.

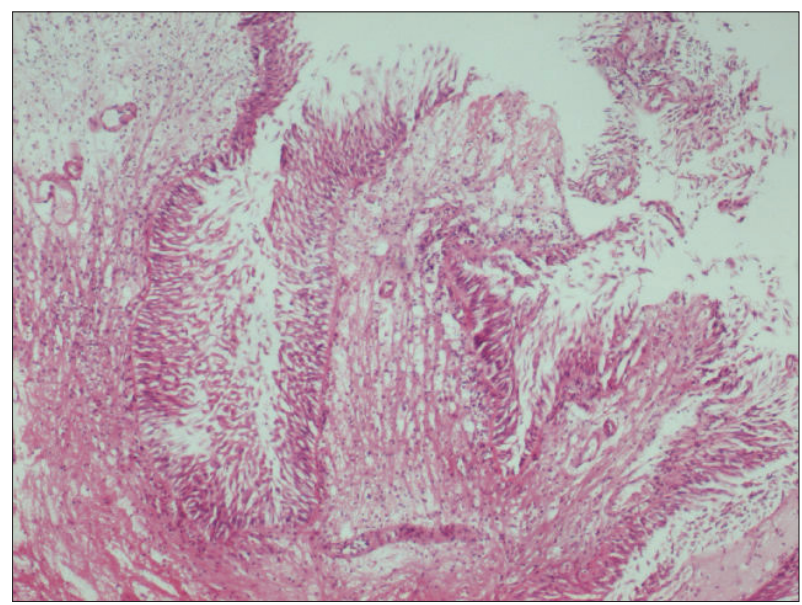

Fig. 2. Histology reveals the tumor's papillary structure with one or more layers of columnar epithelial cells around a fibrovascular core $(\mathrm{H} \& \mathrm{E}, \times 40)$.

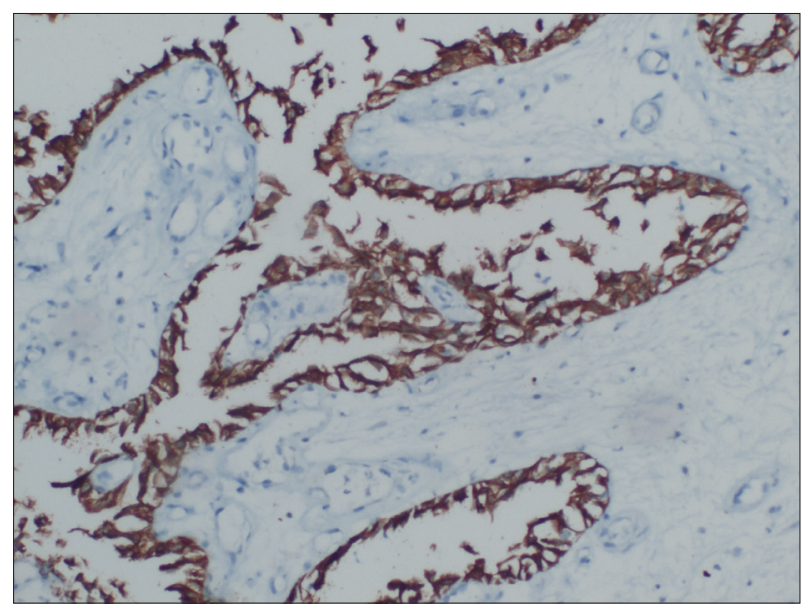

Fig. 3. Micrograph of immunostained section shows positive expression of pancytokeratin $(\times 10)$.

eral ventricles was apparent.

Histopathological investigation revealed papillary structures with a delicate fibrovascular core lined by one or more layers of columnar epithelial cells. Immunohistochemistry found that tumor cells expressed pancytokeratin (pan-CK), but not glial fibrillary acidic protein (GFAP). The tumor was thus diagnosed
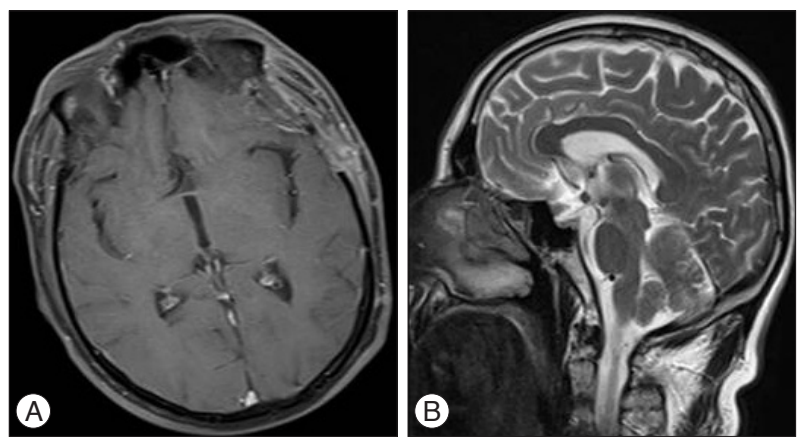

Fig. 4. T1-weighted contrast enhanced axial (A) and T2-weighted sagittal (B) postoperative MRI show total excision of the tumor.
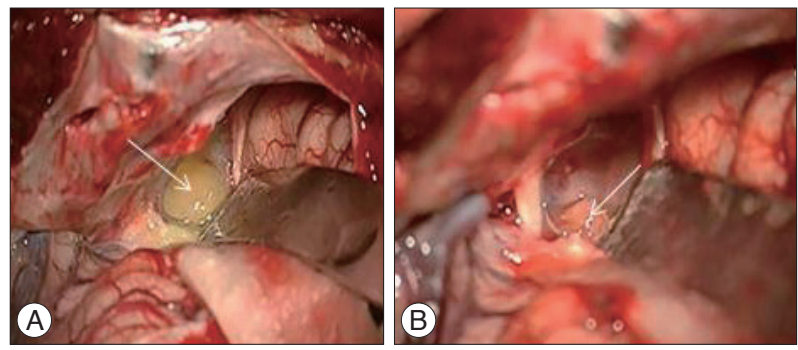

Fig. 5. Intraoperative image. A : The cystic component of the tumor (white arrow). B : Yellowish tumoral nodule (white arrow) after opening the cystic component.

as CPP (Fig. 3, 4). Following surgery, the patient's vision in his left eye improved rapidly and he reported no adverse events or changes in neurological function. Postoperative MRI showed total excision of the tumor (Fig. 5). The patient is currently under outpatient observation.

\section{DISCUSSION}

Choroid plexus papillomas are rare tumors of the central nervous system, representing less than $1 \%$ of all verified intracranial neoplasms ${ }^{11)}$. These neoplasms are commonly confined to the ventricle system, where the choroid plexus is normally located; in the lateral ventricles in infants and children and in the fourth ventricle in adults ${ }^{11)}$. A few reports have described CPPs arising from extraventricular sites such as the posterior third 
Table 1. Summary of previously reported cases

\begin{tabular}{|c|c|c|c|c|c|}
\hline Authors & Year & Age, sex & Symptoms & Tumor site & Treatment \\
\hline Bian et al. ${ }^{4}$ & 2011 & $31, \mathrm{~F}$ & Amenorrhea, galactorrhea & Sellar region & Endonasal transsphenoidal approach \\
\hline Sameshima et al. ${ }^{17)}$ & 2010 & $51, \mathrm{~F}$ & Headache & Sellar-suprasellar region & Endonasal transsphenoidal approach \\
\hline Ma et al. ${ }^{11)}$ & 2008 & $49, \mathrm{~F}$ & Visual Deterioration & Sellar region & Endonasal transsphenoidal approach \\
\hline Kimura et al. ${ }^{9)}$ & 1992 & $34, \mathrm{~F}$ & Visual deterioration & Suprasellar region & Pterional approach \\
\hline
\end{tabular}

ventricle $^{14,15)}$, cerebellopontine angle ${ }^{12,13)}$, posterior fossa ${ }^{3,6)}$, brain stem $^{16)}$, sacral canal $^{10)}$, and cerebral parenchyma ${ }^{7)}$.

CPPs rarely occur in the pituitary fossa and sellar/suprasellar region. To our knowledge, only five cases have been reported in the English-language literature, including our case $e^{4,9,11,17)}$.

In Table 1 we summarize the important features of previously reported cases. The case reported by Winer et al. ${ }^{18)}$ was excluded from this table because of the possibility that the tumor arose in the third ventricle and extended downwards into the sella.

The exact mechanism by which CPPs arise in extraventricular sites remains unclear and is subject to some controversy. Most extraventricular CPPs are located at the cerebellopontine angle (CPA). Tumors in this location can result from herniation of the tumor through the foramen of Luschka or from de novo development in the choroid plexus lying outside the fourth ventricle at the CPA, referred to as Bochdaleck's flower basket ${ }^{4,8)}$.

Two hypotheses have been suggested for the origins of extraventricular intraparenchymal CPPs by Azzam and Timperley ${ }^{1}$ : first, that they might arise from primitive ectopic choroid plexus in the extraventricular site and second, that they may develop from epithelial tissue that migrated to extraventricular areas during brain development. In our case, neuroimaging and operative findings clearly showed that the CPP was not attached to the ventricular choroid plexus and had not metastasized from another CPP. Therefore, we infer that the CPP of the sellar region in our case arose from ectopic choroid plexus tissue as in the cases reported by Bian et al. ${ }^{4)}$, Ma et al. ${ }^{11)}$, and Sameshima et al. ${ }^{17)}$.

Imaging characteristics were not sufficiently distinct to preoperatively diagnose CPP in our case, similar to other reports ${ }^{4,11,17)}$. CPP typically appears on CT as a well-defined, homogeneous enhancing mass with lobulations and a frond-like irregular pattern, resulting in a cauliflower-like appearance ${ }^{10)}$.

Other reported cases ${ }^{4,9,11,17)}$ appeared nearly identical; however, our case had completely different neuroimaging characteristics, including parasellar cystic extension and a hyperintense contrast-enhanced nodule. Overall, distinguishing a CPP from a pituitary adenoma or other pathologies is difficult based only on neuroimaging.

Complete microsurgical excision of the tumor is the recommended therapy and was achieved in our case using a left-sided pterional approach $^{5}$. In other cases the most common neurosurgical procedure is an endonasal transsphenoidal approach ${ }^{4,11,17)}$. The only report of excision via a pterional approach similar to ours is from Kimura et al. ${ }^{9}$. We chose the pterional approach for two reasons : first, the tumor had marked supra- and parasellar extensions and second, it seemed the only safe means of avoiding the suprasellar internal carotid artery. Except for undifferentiated forms of the tumor, CPP does not metastasize through the cerebrospinal fluid $^{2)}$, so postoperative radiotherapy was not considered in our case, similar to previous reports ${ }^{11)}$.

\section{References}

1. Azzam NI, Timperley WR : Intracerebral cyst due to ectopic choroid plexus : case report. J Neurosurg 55 : 651-653, 1981

2. Barreto AS, Vassallo J, Queiroz Lde S : Papillomas and carcinomas of the choroid plexus : histological and immunohistochemical studies and comparison with normal fetal choroid plexus. Arq Neuropsiquiatr 62 (3A) : 600-607, 2004

3. Beskonakli E, Cayli S, Bostanci U, Kulaçoglu S, Yalçinlar Y : Choroid plexus papillomas of the posterior fossa : extraventricular extension, intraventricular and primary extraventricular location. Report of four cases. J Neurosurg Sci 42 : 37-40, 1998

4. Bian LG, Sun QF, Wu HC, Jiang H, Sun YH, Shen JK : Primary choroid plexus papilloma in the pituitary fossa : case report and literature review. Acta Neurochir (Wien) 153: 851-857, 2011

5. Furuya K, Sasaki T, Saito N, Atsuchi M, Kirino T : Primary large choroid plexus papillomas in the cerebellopontine angle : radiological manifestations and surgical management. Acta Neurochir (Wien) 135: 144-149, 1995

6. García-Valtuille R, Abascal F, García-Valtuille AI, Pinto JI, Cerezal L, Sanz F, et al. : Adult choroid plexus papilloma of the posterior fossa mimicking a hemangioblastoma. Case report. J Neurosurg 92 : 870-872, 2000

7. Imai M, Tominaga J, Matsumae $\mathrm{M}$ : Choroid plexus papilloma originating from the cerebrum parenchyma. Surg Neurol Int $2: 151,2011$

8. Jinhu Y, Jianping D, Jun M, Hui S, Yepeng F : Metastasis of a histologically benign choroid plexus papilloma : case report and review of the literature. J Neurooncol 83 : 47-52, 2007

9. Kimura M, Takayasu M, Suzuki Y, Negoro M, Nagasaka T, Nakashima $\mathrm{N}$, et al. : Primary choroid plexus papilloma located in the suprasellar region : case report. Neurosurgery 31 : 563-566, 1992

10. Kurtkaya-Yapicier O, Scheithauer BW, Van Peteghem KP, Sawicki JE : Unusual case of extradural choroid plexus papilloma of the sacral canal. Case report. J Neurosurg 97 (1 Suppl) : 102-105, 2002

11. Ma YH, Ye K, Zhan RY, Wang LJ : Primary choroid plexus papilloma of the sellar region. J Neurooncol 88 : 51-55, 2008

12. McIver JI, Link MJ, Giannini C, Cohen-Gadol AA, Driscoll C : Choroid plexus papilloma and meningioma : coincidental posterior fossa tumors: case report and review of the literature. Surg Neurol $60: 360-365,2003$

13. Mitsuyama T, Ide M, Hagiwara S, Tanaka N, Kawamura H, Aiba M : [Adult choroid plexus papilloma of the posterior fossa : extraventricular location]. No Shinkei Geka 33 : 825-829, 2005

14. Nakano I, Kondo A, Iwasaki K : Choroid plexus papilloma in the posterior third ventricle : case report. Neurosurgery $40: 1279-1282,1997$

15. Noguchi A, Shiokawa Y, Kobayashi K, Saito I, Tsuchiya K, McMenomey SO, et al. : Choroid plexus papilloma of the third ventricle in the fetus. Case illustration. J Neurosurg 100 (2 Suppl Pediatrics) : 224, 2004

16. Pillai A, Rajeev K, Chandi S, Unnikrishnan M : Intrinsic brainstem cho- 
roid plexus papilloma. Case report. J Neurosurg 100 : 1076-1078, 2004 17. Sameshima T, Tanikawa R, Sugimura T, Izumi N, Seki T, Maeda T, et al. : Choroid plexus papilloma originating in the sella turcica--case report.
Neurol Med Chir (Tokyo) 50 : 144-146, 2010

18. Winer JB, Lidov H, Scaravilli F : An ependymoma involving the pituitary fossa. J Neurol Neurosurg Psychiatry 52 : 1443-1444, 1989 